\title{
Bem estar do trabalhador docente de educação física da região sul do Brasil de acordo com os ciclos vitais
}

CDD. 20.ed. 306.361

796.017

\author{
Jorge BOTH* $^{*}$ \\ Juarez Vieira do NASCIMENTO** \\ Christi Noriko SONOO*** \\ Carlos Augusto Fogliarini LEMOS ${ }^{* * * * *}$ \\ Adriano Ferreti BORGATTO ${ }^{* * * * *}$
}

${ }^{*}$ Centro de Educação
Física e Esporte, Uni-
versidade Estadual de
Londrina.
${ }^{* *}$ Centro de Desportos,
Universidade Federal
de Santa Catarina.
${ }_{* * *}$ Centro de Ciências
da Saúde, Univer-
sidade Estadual de
Maringá.
****Universidade Re-
gional Integrada do Alto
Uruguai e das Missões
- Santo Ângelo.
****Centro Tecnológi-
co, Universidade Fede-
ral de Santa Catarina.

\section{Resumo}

0 objetivo do estudo foi avaliar o nível de associação entre os ciclos vitais e os parâmetros socioambiental (satisfação no trabalho) e individual (estilo de vida) do Bem Estar do Trabalhador Docente em Educação Física dos magistérios públicos estaduais da região sul do Brasil. Na investigação, 1645 professores responderam um questionário sócio-demográfico e profissional, além dos instrumentos OVT-PEF e PEVI. Os testes qui-quadrado, razão de verossimilhança e regressão logística multinomial, na forma bruta e em dois modelos ajustados, foram empregados para avaliar as associações. Os resultados evidenciaram que a utilização de variáveis moderadoras nas análises ajustadas do constructo da satisfação no trabalho auxiliou na compreensão das alterações de percepções dos professores ao longo da vida. Situação contrária foi demonstrada na avaliação do estilo de vida, o qual revelou que a análise bruta foi a principal maneira de observar diferenças significativas na maioria dos componentes e no computo geral.

Palavras-chave: Faixa etária; Carreira docente; Satisfação no trabalho; Estilo de vida; Professores; Educação física.

\section{Introdução}

O nível de satisfação no trabalho e o estilo de vida interferem no cotidiano dos trabalhadores, sendo que profissionais motivados profissionalmente e possuidores de um estilo de vida saudável apresentam fatores importantes para a manutenção da saúde ${ }^{1}$. No caso específico da docência, constata-se que patologias físicas e psíquicas não apenas influenciam os aspectos pessoais, mas também interferem na qualidade do trabalho pedagógico, bem como podem onerar os cofres da instituição mantenedora da unidade educativa por eventuais afastamentos por motivo de tratamento de doenças ${ }^{2}$. Ou seja, os problemas relacionados à falta da satisfação no trabalho e um estilo de vida positivo do professor interferem, de alguma forma, nos interesses de todas as pessoas e entidades que estão envolvidas com o processo educativo. Entretanto, a visão do docente sobre os aspectos que intervêm na vida do professor muitas vezes é desconsiderada.
Alguns estudos relacionados a temas que envolvem o Bem Estar do Trabalhador Docente, voltados ao parâmetro socioambiental "trabalho", tanto na realidade brasileira ${ }^{3-4}$ quanto na realidade internacional ${ }^{5-9}$, descrevem que os principais problemas com o trabalho docente na área da Educação Física são: a insatisfação com os salários, condiçôes de trabalho inadequadas, baixo status da disciplina na escola, omissão da direção e equipe pedagógica em questóes pontuais, falta de cursos de capacitação, currículos defasados, sobrecarga de trabalho e burocracia institucional. Por outro lado, no parâmetro individual, associado ao "estilo de vida", as investigaçôes têm apontado os maus hábitos alimentares, o baixo controle do estresse e o moderado comprometimento com atividades físicas habituais enquanto os principais problemas enfrentados pelos docentes de Educação Física ${ }^{9-11}$. Destaca-se que embora não exista uma correlação efetiva entre o estilo de vida 
e a satisfação no trabalho ${ }^{12}$, observa-se que fatores que interferem na vida docente, como a remuneração e os relacionamentos sociais estabelecidos no ambiente de trabalho, podem levar o docente ao pluriemprego ${ }^{13}$, e consequentemente interferir nos comportamentos associados ao nível de atividade física, hábitos alimentares e o controle do estresse ${ }^{14-15}$.

O descontentamento com o trabalho e a adoçáo de um estilo de vida negativo resultam de acontecimentos no decorrer na vida profissional e pessoal $^{8,10-11}$. No caso dos profissionais da educação, os assuntos relacionados às esferas do trabalho e da vida pessoal moldam e alteram crenças e atitudes dos professores, sendo que estes acontecimentos podem ocorrer em casos pontuais ou serem reflexos de costumes do cotidiano ${ }^{16-20}$.

Para compreender o processo da constituição de crenças e valores de professores e demais aspectos que permeiam a carreira docente, alguns investigadores abordaram as histórias de vida profissional e pessoal de docentes, descrevendo a existência de fases ou estágios da vida docente. Estes modelos teóricos buscavam caracterizar os ciclos vitais ${ }^{21}$ ou os ciclos de desenvolvimento profissional dos docentes ${ }^{22-24}$.

Dentre os estudos nesta área, destaca-se a investigação de SiKes ${ }^{21}$, a qual relacionou idade cronológica dos professores com os fatos marcantes pessoais e profissionais para delimitar cinco etapas dos ciclos vitais dos docentes:

- 21 e 28 anos de idade: Ocorre exploração da vida adulta, além do começo da busca da vida estável. Em relação ao trabalho, os professores se preocupam com os problemas com a indisciplina, devido à ausência de autoridade, além do domínio do conteúdo;

- 28 e 33 anos de idade: Acontece um momento de transição, no qual surge a estabilidade no posto de trabalho para alguns docentes e a busca de novo emprego para outros professores. Neste momento os professores estão mais preocupados com o ensino do que o domínio do conteúdo;

- 30 e 40 anos de idade: Os docentes apresentam grande capacidade física e intelectual, o que significa ambição, confiança e energia em si mesmos. Período em que o professor busca ser mais competente com o seu trabalho, bem como, almeja a promoção na carreira docente. Destaca-se que para as professoras ocorre uma tensão relacionada à maternidade e a atenção com os filhos. Por outro lado, os fatores positivos desta fase são: o fato de ser mãe/pai, onde surge um sentimento de dedicação pessoal e maior compreensão dos alunos, e o matrimônio que pode proporcionar estabilidade e confiança para muitos professores;

- 40 e 50/55 anos de idade: Os professores se adaptam ao estágio maduro da vida, adotando novos papéis na escola e no sistema educativo. Normalmente, são os professores que possuem muitas responsabilidades na unidade educativa, além de manter os princípios e tradiçóes no ambiente escolar. Possuem esta conduta, pois pensam que são eles que devem ter este comportamento na escola. Entretanto, nem todos os professores apresentam esta reação, sendo que alguns docentes não se adaptam às mudanças administrativas e metodológicas de ensino, tornando-se assim, amargos, críticos e cínicos frente ao processo educativo;

- 50 e 55 anos de idade: Neste momento ocorre à aposentadoria ou a preparação da aposentadoria. Os professores têm a tendência de relaxar com a disciplina e cobrança das atividades com os alunos.

Destaca-se que no modelo de ciclos vitais de SIKES ${ }^{21}$, algumas fases se sobrepóem pelo fato de existir momentos de transição, onde os professores demonstram características profissionais e pessoais semelhantes, entretanto, com açóes e perspectivas diferentes.

Embora alguns estudos tenham abordado a faixa etária dos professores como variável de estudo ${ }^{25-26}$, são escassas as investigaçôes que consideraram diferentes momentos pessoais e profissionais durante a vida dos docentes como é referenciado no modelo teórico dos ciclos vitais de SiKes ${ }^{21}$. Assim, ao considerar a importância da compressão das relaçóes entre os ciclos vitais dos professores com o Bem Estar do Trabalhador Docente, tanto no parâmetro socioambiental quanto no parâmetro individual, realizou-se exaustiva pesquisa nas bases indexadoras de periódicos para verificar a relação existente entre essas variáveis. Diante da escassez de estudos desta natureza na realidade brasileira e internacional, o presente estudo foi realizado com o objetivo de avaliar o nível de associação entre os ciclos vitais dos docentes de Educação Física dos magistérios públicos estaduais dos ensinos fundamental e médio da região sul do Brasil com a satisfação no trabalho (parâmetro socioambiental) e o estilo de vida (parâmetro individual) do Bem Estar do Trabalhador Docente. 


\section{Método}

O estudo caracterizou-se como descritivo, de corte transversal, tendo como população, os professores efetivos de Educação Física dos magistérios públicos estaduais das unidades federativas do Rio Grande do Sul, Santa Catarina e Paraná. A seleção da amostra ocorreu em dois estratos e um estágio. $\mathrm{O}$ primeiro estrato considerou os estados que compóe a região sul do Brasil, o segundo considerou todas as mesorregiōes de cada Estado (seis mesorregióes no Rio Grande do Sul, seis mesorregiôes em Santa Catarina e cinco mesorregióes no Paraná). O único estágio considerou os núcleos regionais de ensino (NREs) como conglomerados das mesorregióes dos seus respectivos Estados. Nas mesorregióes que possuíam no mínimo quatro NREs eram sorteados, no mínimo, três conglomerados. Nas mesorregiōes que possuíam até três NREs, todos os conglomerados participaram do procedimento de coleta de dados.

Para a operacionalização da investigaçẫo, solicitouse inicialmente a autorização dos órgãos máximos da educação estatal, de cada unidade federativa, para que o projeto de pesquisa pudesse ser aprovado no Comitê de Ética em Pesquisa com Seres Humanos da Universidade Federal de Santa Catarina (Parecer $n^{\circ}$ 036/07). Após esta fase, realizaram-se contatos telefônicos com os NREs sorteados na coleta de dados. Tal açáo solicitava auxílio aos NREs por meio da utilização do serviço de mala direta que estes órgãos administrativos educacionais possuem com as escolas.

Para a coleta de dados foram enviados instrumentos para todos os professores vinculados aos conglomerados selecionados (NREs) para participar da coleta de dados, o que corresponde a um total de 5.734 questionários envidados. O retorno dos instrumentos para os pesquisadores foi de $28,69 \%$, o que demonstra que 1.645 dos professores (654 docentes do Paraná, 580 de Santa Catarina e 411 do Rio Grande do Sul) retornaram os questionários respondidos. Ao final da coleta de dados, pode-se estabelecer no estudo o erro amostral de 2,27 pontos percentuais, com intervalo de confiança de 95\%, obtidos através do programa Epi-Info 3.5.1.

Os instrumentos de coleta de dados compreenderam um questionário sobre os aspectos sóciodemográficos e profissionais dos docentes, a "Escala de Avaliação da Qualidade de Vida no Trabalho Percebida por Professores de Educação Física do Ensino Fundamental e Médio" (QVT-PEF) ${ }^{27}$ e o "Perfil do Estilo de Vida Individual" (PEVI) ${ }^{28}$.

O QVT-PEF é composto por 34 questôes, as quais estão distribuídas em oito dimensões baseadas nos indicadores criados por WALTON ${ }^{29}$ : remuneração; condiçóes de trabalho; autonomia no trabalho; oportunidade de progressão na carreira; integração social no ambiente de trabalho; leis e normas do trabalho; trabalho e espaço total de vida; relevância social do trabalho. Na avaliação do QVT-PEF constatou-se alto nível de consenso entre os especialistas sobre a temática abordada no questionário (acima de 70,0\%). As questōes obtiveram, no mínimo, moderada correlação (acima de $\mathrm{r}_{\mathrm{s}}$ 0,484), e em todas dimensōes evidenciou-se forte correlação (acima de $r_{s} 0,693$ ). Por fim, a consistência interna do instrumento obteve excelente índice (alfa de Cronbach de 0,9482) ${ }^{27}$.

O PEVI é composto por 15 questôes distribuídas em cinco componentes: alimentação, atividade física, comportamento preventivo, relacionamentos e controle do estresse ${ }^{28}$. Na validação do PEVI, efetuada por Both et al. ${ }^{30}$, constatou-se que as questôes estavam bem distribuídas, a consistência interna foi considerada razoável (alfa de Cronbach de 0,78). Além disso, as questóes não demonstraram conflito de interesse entre si, por apresentarem, no máximo, níveis moderados de correlação $\left(\mathrm{r}_{\mathrm{s}}>0,60\right)$.

$\mathrm{Na}$ análise dos dados foram empregadas equaçóes de ponderaçáo de $\operatorname{Lemos}^{31}$ para categorizar as dimensôes/componentes e a avaliaçáo global, tanto no constructo da satisfaçáo do trabalho quanto no constructo do estilo de vida. Na sequência foram atribuídos pesos aos participantes da investigação, a partir da probabilidade de seleção do professor, devido à amostragem utilizada não ter sido ao simples ao acaso.

A análise estatística compreendeu a associação entre os ciclos vitais e aspectos sócio-demográficos e profissionais, satisfaçáo no trabalho e estilo de vida. Enquanto que o teste qui-quadrado foi utilizado na análise dos ciclos vitais e os aspectos sócio-demográficos e profissionais, a análise de tendência da variável ciclos vitais foi verificada por meio do teste qui-quadrado para grupo único, tendo como referência $25,0 \%$.

$\mathrm{O}$ teste razão de verossimilhança no modelo de regressão logística multinomial foi empregado para constatar as associaçôes significativas entre as variáveis ciclos vitais (variável independente) e as dimensôes/componentes, bem como, as avaliações globais da satisfação no trabalho e do estilo de vida (variáveis dependentes). Além disso, as análises pormenorizadas da regressão logística multinomial foram realizadas tanto na forma bruta, quanto em dois modelos ajustados ("odds ratio" - OR; intervalo de confiança de 95\% - IC95\%). 
O primeiro modelo considerou como variáveis moderadoras (de controle) todas as questôes relacionadas ao estilo de vida, satisfaçáo no trabalho e aspectos sócio-demográficos e profissionais dos docentes. O segundo modelo foi composto pelas seguintes variáveis moderadoras: unidade da federação, sexo, estado civil, ciclos de desenvolvimento profissional, formaçâo acadêmica, carga horária semanal, tempo de serviço, pluriemprego, remuneração, condiçôes de trabalho, oportunidade de progressão na carreira, avaliação global da satisfação no trabalho, alimentação, atividade fisica, comportamento preventivo, relacionamentos, controle do estresse e avaliaçáo global do estilo de vida. A escolha das variáveis do segundo modelo deu-se a partir das análises realizadas através do teste qui-quadrado (ciclos vitais "versus" aspectos sóciodemográficos e profissionais) e da análise bruta do teste de razão de verossimilhança (ciclos vitais versus constructo da satisfação no trabalho e ciclos vitais versus constructo do estilo de vida) deste estudo que apresentaram um p-valor igual ou menor a 0,10. A

\section{Resultados}

Ao avaliar as proporçóes de docentes considerando os ciclos vitais, observou-se que a maioria dos professores está alocada nos ciclos de 30 a 39 anos $(34,5 \%)$ e 40 a 49 anos $(37,6 \%)(\mathrm{p}<0,01)$. Além justificativa de utilizar o ponto de corte de $\mathrm{p}<0,10$ está alicerçada no estabelecimento de um critério mais rígido para determinar as variáveis moderadoras que deveriam ser consideradas na montagem do segundo modelo ajustado.

Destaca-se que foram isoladas as categorias dos professores indecisos no constructo da satisfação no trabalho e dos docentes que possuíam comportamentos intermediários no constructo do estilo de vida nas análises de regressão logística multinomial para estabelecer, respectivamente, as razóes de chance dos professores insatisfeitos e satisfeitos com o trabalho e dos professores com perfil negativo e positivo no estilo de vida. Os testes estatísticos foram realizados no programa SPSS, versão 15.0 , adotando o nível de significância de $5 \%(\mathrm{p}<0,05)$.

$\mathrm{Na}$ análise da variável ciclos vitais foi necessário realizar uma adaptação dos ciclos propostos por Sikes ${ }^{21}$, estabelecendo-se os seguintes pontos de corte: até 29 anos, 30 a 39 anos, 40 a 49 anos e 50 anos ou mais.

TABELA 1 - Aspectos sócio-demográficos e profissionais da amostra considerando os Ciclos Vitais.

*p estimado pelo teste Qui-quadrado.

${ }^{* *}$ p estimado pelo teste Qui-quadrado para grupo único.

\begin{tabular}{|c|c|c|c|c|c|}
\hline $\begin{array}{c}\text { Aspectos Sócio-demográficos } \\
\text { e Profissionais }\end{array}$ & \multicolumn{4}{|c|}{ Ciclos Vitais } & $\mathbf{p}$ \\
\hline \multicolumn{5}{|l|}{ Unidade da Federaçáo } & $<0,01^{*}$ \\
\hline Paraná & 45,9 & 35,7 & 28,7 & 30,3 & \\
\hline Santa Catarina & 16,1 & 12,5 & 13,2 & 17,4 & \\
\hline \multicolumn{5}{|l|}{ Sexo } & $<0,01^{*}$ \\
\hline Masculino & 44,7 & 36,3 & 39,1 & 58,5 & \\
\hline Feminino & 55,3 & 63,7 & 60,9 & 41,5 & \\
\hline \multicolumn{5}{|l|}{ Estado civil } & $<0,01^{*}$ \\
\hline
\end{tabular}

disso, constatou-se associação significativa $(\mathrm{p}<0,01)$ em todas as análises realizadas entre os ciclos vitais e os aspectos sócio-demográficos e profissionais elencados neste estudo (TABELA 1). 
TABELA 1 - Aspectos sócio-demográficos e profissionais da amostra considerando os Ciclos Vitais (continuação).

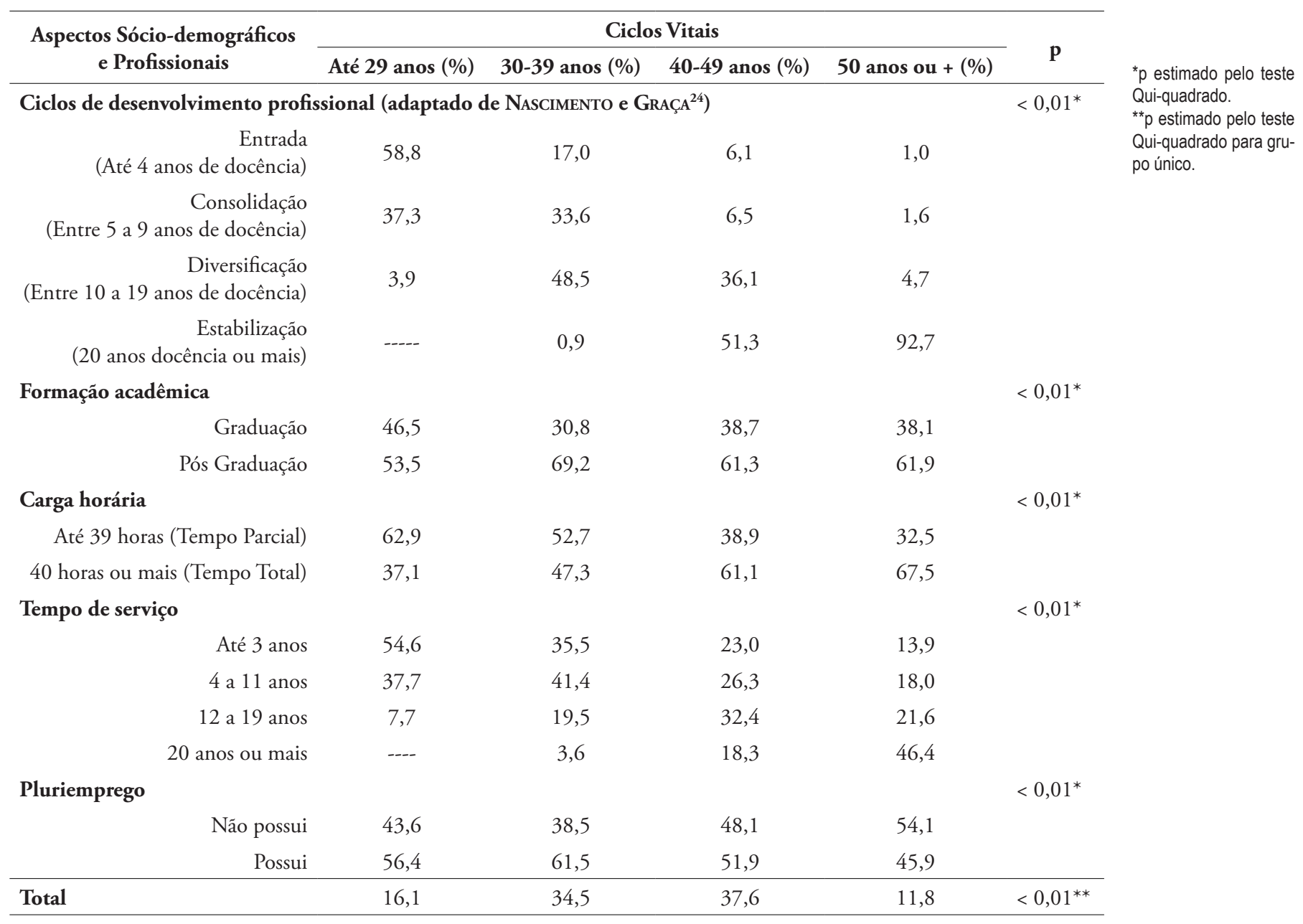

A formação acadêmica foi à única variável que demonstrou que a maioria dos professores de todos os ciclos vitais relatou ter realizado pós-graduação. Destaca-se que os professores com 30 a 39 anos apresentaram o maior índice $(69,2 \%)$, enquanto que os docentes com até 29 anos a menor frequência (53,5\%). Nas demais variáveis, a maioria dos professores de Educação Física de cada ciclo vital informou que:

- Até 29 anos: Professores do Paraná (45,9\%); são mulheres $(55,3 \%)$; não são casados $(63,4 \%)$; estão no ciclo de entrada $(58,8 \%)$ da carreira docente; trabalham até 39 horas semanais $(62,9 \%)$; possuem vinculo empregatício com o Estado até três anos (54,6\%); e possuem a característica do pluriemprego $(56,4 \%)$.

- 30 a 39 anos: Professores do Rio Grande do Sul (51,8\%); são mulheres (63,7\%); são casados $(66,9 \%)$; estão no ciclo de diversificação $(48,5 \%)$ da carreira docente; trabalham até 39 horas semanais (52,7\%); possuem vinculo empregatício com o Estado entre a faixa de quatro a 11 anos (41,4\%); e possui o pluriemprego (61,5\%).

- 40 a 49 anos: Professores do Rio Grande do Sul (58,1\%); são mulheres (60,9\%); são casados
(71,8\%); estão no ciclo de estabilização $(51,3 \%)$ da carreira docente; trabalham 40 horas semanais ou mais $(61,1 \%)$; possuem vinculo empregatício com o Estado entre a faixa de 12 a 19 anos (32,4\%); e possui o pluriemprego $(51,9 \%)$.

- 50 anos ou mais: Professores do Rio Grande do Sul (52,3\%); são homens (58,5\%); são casados (64,6\%); estão no ciclo de estabilização $(92,7 \%)$ da carreira docente; trabalham 40 horas semanais ou mais $(67,5 \%)$; possuem vinculo empregatício com o Estado entre a faixa de 20 anos ou mais $(46,4 \%)$; e não possui o pluriemprego $(54,1 \%)$.

Em relação ao constructo da satisfação no trabalho (TABELA 2), observou-se que a maioria dos docentes está insatisfeita com a remuneração. Outros fatores que merecem destaque para o baixo índice de satisfação docente foram as condições de trabalho, trabalho e espaço total de vida e integração social no ambiente de trabalho. Destaca-se que a maioria dos professores estavam satisfeitos na avaliação global da satisfação no trabalho. 
Both J. et al.

TABELA 2 - Nível de Satisfação no Trabalho considerando os Ciclos Vitais.

${ }^{*} p$ estimado pelo teste da razão de verossimiIhança;

+Os aspectos moderadores neste modelo de análise são todas as variáveis dos aspectos sócio demográficos e profissionais e dos constructos da satisfação no trabalho e do estilo de vida que foram relacionados com os ciclos vitais. Destaca-se que a variável dependente de cada análise foi excluída do modelo ajustado no momento de sua análise;

++Os aspectos moderadores neste modelo de análise são todas as variáveis que evidenciaram um $p<0,10$ nas análises com os ciclos vitais (qui-quadrado e teste de razão de verossimilhança), as quais são: unidade da federação, sexo, estado civil, ciclos de desenvolvimento profissional, formação acadêmica, carga horária semanal, tempo de serviço, pluriemprego, remuneração, condições de trabalho, oportunidade de progressão na carreira, avaliação global da satisfação no trabalho, alimentação, atividade física, comportamento preventivo, relacionamentos, controle do estresse e avaliação global do estilo de vida. Destaca-se que a variável dependente de cada análise foi excluída do modelo ajustado no momento de sua análise.

\begin{tabular}{|c|c|c|c|c|c|c|}
\hline \multirow{2}{*}{ Ciclos Vitais } & \multicolumn{3}{|c|}{ Satisfaçáo no Trabalho } & \multirow{2}{*}{ p bruto* } & \multirow{2}{*}{$\begin{array}{c}\text { p do } 1^{\circ} \\
\text { modelo* }\end{array}$} & \multirow{2}{*}{$\begin{array}{c}\mathrm{p} \text { do } 2^{\circ} \\
\text { modelo* }^{*}++\end{array}$} \\
\hline & Insatisfeitos (\%) & Indecisos (\%) & Satisfeitos (\%) & & & \\
\hline Remuneraçáo & & & & $<0,01$ & $<0,01$ & $<0,01$ \\
\hline Até 29 anos & 41,4 & 38,0 & 20,5 & & & \\
\hline 30-39 anos & 56,9 & 29,1 & 14,0 & & & \\
\hline 40-49 anos & 56,1 & 30,4 & 13,5 & & & \\
\hline 50 anos ou + & 56,2 & 32,8 & 10,9 & & & \\
\hline \multicolumn{3}{|c|}{ Condiçóes de trabalho } & & $<0,01$ & $<0,01$ & 0,01 \\
\hline Até 29 anos & 29,3 & 38,0 & 32,7 & & & \\
\hline 30-39 anos & 34,2 & 28,4 & 37,4 & & & \\
\hline 40-49 anos & 27,3 & 29,8 & 42,9 & & & \\
\hline 50 anos ou + & 23,4 & 29,4 & 47,3 & & & \\
\hline \multicolumn{3}{|c|}{ Autonomia no trabalho } & & 0,46 & 0,75 & 0,84 \\
\hline Até 29 anos & 2,3 & 21,6 & 76,1 & & & \\
\hline 30-39 anos & 3,9 & 21,1 & 75,1 & & & \\
\hline 40-49 anos & 4,9 & 19,2 & 75,9 & & & \\
\hline 50 anos ou + & 5,5 & 17,9 & 76,6 & & & \\
\hline \multicolumn{4}{|c|}{ Oportunidade de progressáo na carreira } & 0,08 & 0,06 & 0,01 \\
\hline Até 29 anos & 4,9 & 23,5 & 71,6 & & & \\
\hline 30-39 anos & 6,7 & 24,7 & 68,6 & & & \\
\hline 40-49 anos & 7,5 & 18,0 & 74,5 & & & \\
\hline 50 anos ou + & 9,0 & 20,4 & 70,6 & & & \\
\hline \multicolumn{4}{|c|}{ Integraçáo social no ambiente de trabalho } & 0,11 & 0,74 & 0,88 \\
\hline Até 29 anos & 11,4 & 39,5 & 49,0 & & & \\
\hline 30-39 anos & 11,8 & 38,2 & 50,0 & & & \\
\hline 40-49 anos & 9,9 & 34,0 & 56,1 & & & \\
\hline 50 anos ou + & 8,5 & 31,3 & 60,2 & & & \\
\hline \multicolumn{4}{|c|}{ Leis e normas do trabalho } & 0,70 & $<0,01$ & 0,47 \\
\hline Até 29 anos & 4,2 & 18,2 & 77,7 & & & \\
\hline 30-39 anos & 5,6 & 17,7 & 76,7 & & & \\
\hline 40-49 anos & 5,8 & 14,8 & 79,4 & & & \\
\hline 50 anos ou + & 6,0 & 17,9 & 76,1 & & & \\
\hline \multicolumn{4}{|c|}{ Trabalho e espaço total de vida } & 0,23 & 0,13 & 0,03 \\
\hline Até 29 anos & 23,9 & 25,0 & 51,1 & & & \\
\hline 30-39 anos & 22,1 & 31,8 & 46,1 & & & \\
\hline 40-49 anos & 24,4 & 31,2 & 44,4 & & & \\
\hline 50 anos ou + & 19,4 & 34,8 & 45,8 & & & \\
\hline \multicolumn{4}{|c|}{ Relevância social do trabalho } & 0,93 & 0,18 & 0,12 \\
\hline Até 29 anos & 4,5 & 18,6 & 76,9 & & & \\
\hline 30-39 anos & 3,7 & 15,6 & 80,7 & & & \\
\hline 40-49 anos & 4,4 & 15,9 & 79,7 & & & \\
\hline 50 anos ou + & 4,0 & 15,9 & 80,1 & & & \\
\hline \multicolumn{4}{|c|}{ Avaliaçáo global da satisfaçáo no trabalho } & 0,04 & 0,78 & $<0,01$ \\
\hline Até 29 anos & 7,2 & 27,4 & 65,4 & & & \\
\hline 30-39 anos & 7,2 & 30,5 & 62,3 & & & \\
\hline 40-49 anos & 9,0 & 23,7 & 67,3 & & & \\
\hline 50 anos ou + & 9,5 & 19,4 & 71,1 & & & \\
\hline
\end{tabular}

82 • Rev Bras Educ Fís Esporte, (São Paulo) 2014 Jan-Mar; 28(1):77-93 
Quando analisados os ciclos vitais considerando o constructo da satisfação no trabalho observou que as dimensões remuneração e condições de trabalho obtiveram associação significativa tanto na avaliação bruta, quanto no primeiro e segundo modelos ajustados de análise $(p<0,01)$. As dimensões oportunidade de progressão na carreira $(\mathrm{p}=0,01)$ e trabalho e espaço total de vida ( $\mathrm{p}=0,03)$ obtiveram associação significativa apenas no segundo modelo ajustado da análise, enquanto que a dimensão: leis e normas do Trabalho demonstrou associação apenas no primeiro modelo ajustado de análise $(\mathrm{p}<0,01)$. Por fim, a avaliação global da satisfação no trabalho evidenciou associações significativas na avaliação bruta $(\mathrm{p}=0,04)$ e no segundo modelo ajustado de análise $(\mathrm{p}<0,01)$ (TABELA 2).
Ao constatar as associaçóes significativas no teste de razão de verossimilhança, foram realizadas as regressóes logísticas multinomiais para encontrar as razóes de chances (TABELA 3). Destaca-se que na análise do primeiro modelo ajustado da regressão logística multinomial na dimensão leis e normas do trabalho não foram encontradas razóes de chances significativas quando considerada a categoria "indeciso" da satisfação no trabalho como referência no estudo. Entretanto, na análise geral foi possível identificar que os professores que possuem entre 40 e 49 anos possuíam menor índice de indecisão (14,8\%), bem como, apresentavam maior frequência de satisfação $(79,4 \%)$ nas opiniōes referentes às questões legais que regem a sua função laboral.

TABELA 3 - Razões de Chances e Intervalos de Confiança (IC95\%) das associações significativas entre os Ciclos Vitais e a Satisfação no Trabalho.

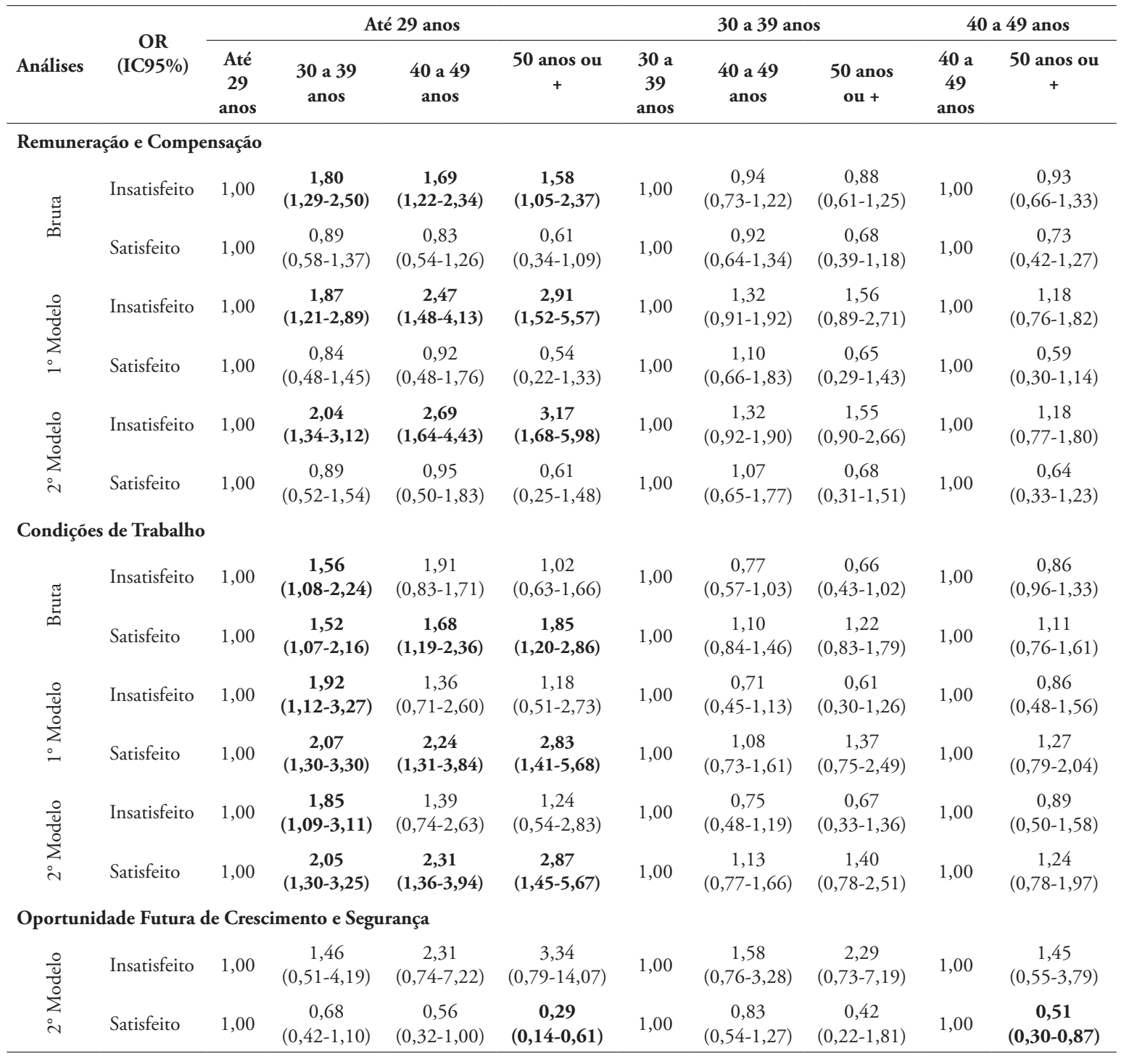

Continua 
TABELA 3 - Razões de Chances e Intervalos de Confiança (IC95\%) das associações significativas entre os Ciclos Vitais e a Satisfação no Trabalho (continuação).

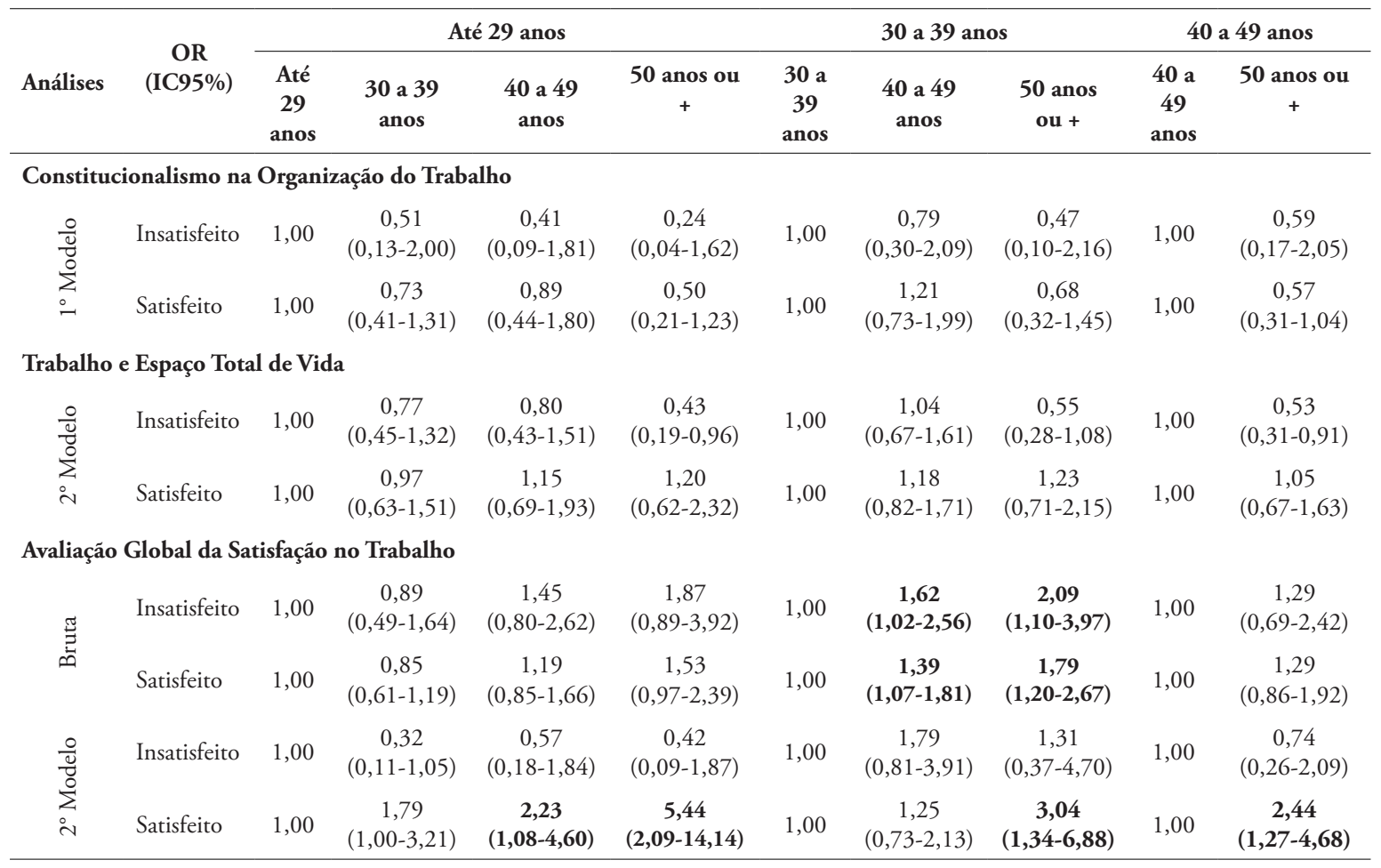

No que diz respeito às dimensóes que demonstraram diferenças nas análises da regressão logística multinomial, constatou-se que a dimensão remuneração apresentou tanto na análise bruta, quanto no primeiro e segundo modelo de análise ajustada que os professores com até 29 anos de idade $(41,4 \%)$ possuíam maior índice de insatisfação que os docentes entre 30 e 39 anos (56,9\%), 40 e 49 anos $(56,1 \%)$ e 50 anos ou mais $(56,2 \%)$.

$\mathrm{Na}$ dimensão condiçôes de trabalho, evidenciouse tanto no primeiro e segundo modelos de análise, quanto na análise bruta da regressão logística multinomial, que os docentes com até 29 anos (29,3\%) de idade demonstraram menor frequência de insatisfação que os professores entre 30 e 39 anos (34,2\%). Destaca-se ainda que os docentes com até 29 anos $(32,7 \%)$ de idade possuíam menor frequência de satisfação que os docentes com 30 a 39 anos (37,4\%), 40 a 49 anos $(42,9 \%)$ e 50 anos ou mais (47,3\%).

A dimensão oportunidade de progressão na carreira demonstrou associação apenas no segundo modelo da análise ajustada, no qual os docentes com 50 anos ou mais $(70,6 \%)$ possuíam menor frequência de satisfação que os professores com até 29 anos $(71,6 \%)$. Além disso, os professores com 40 a 49 anos $(74,5 \%)$ possuíam maior índice de satisfação que os docentes com 50 anos ou mais $(70,6 \%)$.
Sobre a dimensão trabalho e espaço total de vida, constatou-se associação significativa apenas no segundo modelo da análise ajustada, onde os professores com 50 anos ou mais de idade (19,4\%) possuíam menor índice de insatisfaçáo que os docentes entre 40 e 49 anos (24,4\%).

$\mathrm{Na}$ avaliação global da satisfação do trabalho observou-se associações significativas distintas em cada tipo de análise. Enquanto que a análise bruta demonstrou que os docentes entre 30 e 39 anos $(7,2 \%)$ de idade possuíam menor freqüência de insatisfaçáo que os professores com 40 a 49 anos $(9,0 \%)$ e 50 anos ou mais $(9,5 \%)$; e os professores entre 30 e 39 anos $(62,3 \%)$ possuíam menor índice de satisfação que os professores entre 40 e 49 anos $(67,3 \%)$ e 50 anos ou mais $(71,1 \%)$. No segundo modelo da análise ajustada evidenciou-se que os docentes com 50 anos ou mais $(71,1 \%)$ possuíam maior índice de satisfação que os professores entre 40 e 49 anos (67,3\%), 30 e 39 anos $(62,3 \%)$ e com até 29 anos de idade (65,4\%). Além disso, observou-se que os docentes entre 40 e 49 anos de idade $(67,3 \%)$ apresentaram maior frequência de satisfação que os professores com até 29 anos de idade $(65,4 \%)$.

Em relaçáo ao constructo do estilo de vida (TABELA 4), constatou-se baixo índice de comportamentos positivos nos componentes: 
alimentação, controle do estresse e atividade física. do estilo de vida, a qual demonstrou que a maioria Estes resultados influenciaram na avaliação global dos professores possuía comportamento positivo.

TABELA 4 - Perfil do Estilo de Vida considerando os Ciclos Vitais.

\begin{tabular}{|c|c|c|c|c|c|c|}
\hline \multirow{2}{*}{ Ciclos Vitais } & \multicolumn{3}{|c|}{ Estilo de Vida } & \multirow{2}{*}{ p bruto* } & \multirow{2}{*}{$\begin{array}{c}\mathrm{p} \text { do } 1^{\circ} \\
\text { modelo*+ }\end{array}$} & \multirow{2}{*}{$\begin{array}{c}\mathrm{p} \text { do } 2^{\circ} \\
\text { modelo* }{ }^{*}+\end{array}$} \\
\hline & Negativo(\%) & Intermediário(\%) & Positivo(\%) & & & \\
\hline Alimentaçáo & & & & $<0,01$ & 0,30 & 0,26 \\
\hline Até 29 anos & 31,2 & 38,0 & 30,8 & & & \\
\hline 30-39 anos & 31,2 & 35,6 & 33,2 & & & \\
\hline 40-49 anos & 26,5 & 26,7 & 46,8 & & & \\
\hline 50 anos ou + & 32,0 & 30,5 & 37,5 & & & \\
\hline Atividade física & & & & $<0,01$ & 0,07 & 0,13 \\
\hline Até 29 anos & 12,5 & 26,9 & 60,6 & & & \\
\hline 30-39 anos & 23,1 & 20,7 & 56,2 & & & \\
\hline 40-49 anos & 16,9 & 22,6 & 60,5 & & & \\
\hline 50 anos ou + & 22,9 & 22,9 & 54,2 & & & \\
\hline \multicolumn{2}{|c|}{ Comportamento preventivo } & & & $<0,01$ & 0,09 & 0,10 \\
\hline Até 29 anos & 9,5 & 17,0 & 73,5 & & & \\
\hline 30-39 anos & 5,6 & 14,9 & 79,5 & & & \\
\hline $40-49$ anos & 6,3 & 9,3 & 84,4 & & & \\
\hline 50 anos ou + & 13,9 & 6,5 & 79,6 & & & \\
\hline Relacionamentos & & & & 0,07 & 0,02 & 0,05 \\
\hline Até 29 anos & 3,4 & 10,3 & 86,3 & & & \\
\hline 30-39 anos & 5,6 & 16,1 & 78,3 & & & \\
\hline 40-49 anos & 6,7 & 15,9 & 77,4 & & & \\
\hline 50 anos ou + & 4,5 & 14,4 & 81,1 & & & \\
\hline \multicolumn{2}{|c|}{ Controle do estresse } & & & $<0,01$ & 0,08 & 0,78 \\
\hline Até 29 anos & 24,0 & 19,0 & 57,0 & & & \\
\hline 30-39 anos & 22,1 & 30,5 & 47,5 & & & \\
\hline $40-49$ anos & 18,3 & 27,4 & 54,2 & & & \\
\hline 50 anos ou + & 21,4 & 28,4 & 50,2 & & & \\
\hline \multicolumn{3}{|c|}{ Avaliaçáo global do estilo de vida } & & 0,01 & 0,30 & 0,32 \\
\hline Até 29 anos & 4,2 & 27,0 & 68,8 & & & \\
\hline 30-39 anos & 6,7 & 29,6 & 63,7 & & & \\
\hline 40-49 anos & 4,4 & 25,4 & 70,2 & & & \\
\hline 50 anos ou + & 10,9 & 24,9 & 64,2 & & & \\
\hline
\end{tabular}

* $p$ estimado pelo teste da razão de verossimiIhança;

+Os aspectos moderadores neste modelo de análise são todas as variáveis dos aspectos sócio demográficos e profissionais e dos constructos da satisfação no trabalho e do estilo de vida que foram relacionados com os ciclos vitais. Destaca-se que a variável dependente de cada análise foi excluída do modelo ajustado no momento de sua análise; ++ Os aspectos moderadores neste modelo de análise são todas as variáveis que evidenciaram um $p<0,10$ nas análises com os ciclos vitais (qui-quadrado e teste de razão de verossimilhança), as quais são: unidade da federação, sexo, estado civil, ciclos de desenvolvimento profissional, formação acadêmica, carga horária semanal, tempo de serviço, pluriemprego, remuneração, condições de trabalho, oportunidade de progressão na carreira, avaliação global da satisfação no trabalho, alimentação, atividade física, comportamento preventivo, relacionamentos, controle do estresse e avaliação global do estilo de vida. Destaca-se que a variável dependente de cada análise foi excluída do modelo ajustado no momento de sua análise.

$\mathrm{Na}$ análise dos ciclos vitais, considerando o constructo do estilo de vida, constatou-se que os componentes: alimentação $(\mathrm{p}<0,01)$, atividade física ( $\mathrm{p}<0,01)$, comportamento preventivo ( $\mathrm{p}<$ $0,01)$, controle do estresse $(p<0,01)$, bem como a avaliação global do estilo de vida $(\mathrm{p}=0,01)$ obtiveram associação significativa apenas na análise bruta. Por outro lado, o componente relacionamentos apresentou associação significativa no primeiro ( $\mathrm{p}$ $=0,02)$ e segundo $(p=0,05)$ modelos das análises ajustadas (TABELA 4).

No componente alimentação, apenas a análise bruta revelou que os professores dos ciclos vitais de 40 a 49 anos $(46,8 \%)$ relataram com maior frequência comportamentos positivos do que os docentes com até 29 anos $(30,8 \%)$ e 30 e 39 anos (33,2\%). 
TABELA 5 - Razões de Chances e Intervalos de Confiança (IC95\%) das associações significativas entre os Ciclos Vitais e o Estilo de Vida.

\begin{tabular}{|c|c|c|c|c|c|c|c|c|c|c|}
\hline Análises & $\begin{array}{c}\text { OR } \\
\text { (IC95\%) }\end{array}$ & \multicolumn{4}{|c|}{ Até 29 anos } & \multicolumn{3}{|c|}{30 a 39 anos } & \multicolumn{2}{|c|}{40 a 49 anos } \\
\hline \multicolumn{11}{|c|}{ Alimentaçáo } \\
\hline 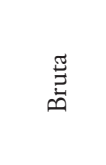 & Negativo & 1,00 & $\begin{array}{c}1,08 \\
(0,76-1,53)\end{array}$ & $\begin{array}{c}1,22 \\
(0,85-1,76)\end{array}$ & $\begin{array}{c}1,29 \\
(0,82-2,03)\end{array}$ & 1,00 & $\begin{array}{c}1,14 \\
(0,85-1,53)\end{array}$ & $\begin{array}{c}1,20 \\
(0,80-1,79)\end{array}$ & 1,00 & $\begin{array}{c}1,05 \\
(0,70-1,59)\end{array}$ \\
\hline \multicolumn{11}{|c|}{ Atividade física } \\
\hline$\underbrace{\mathbb{Z}}_{\mathscr{E}}$ & Negativo & 1,00 & $\begin{array}{c}2,41 \\
(1,48-3,90)\end{array}$ & $\begin{array}{c}1,61 \\
(0,99-2,62)\end{array}$ & $\begin{array}{c}2,19 \\
(1,22-3,91)\end{array}$ & 1,00 & $\begin{array}{c}0,67 \\
(0,47-0,96)\end{array}$ & $\begin{array}{c}0,91 \\
(0,56-1,46)\end{array}$ & 1,00 & $\begin{array}{c}1,36 \\
(0,84-2,20)\end{array}$ \\
\hline \multirow{2}{*}{$\underset{\mathscr{D}}{\tilde{E}}$} & Negativo & 1,00 & $\begin{array}{c}0,69 \\
(0,37-1,31)\end{array}$ & $\begin{array}{c}1,24 \\
(0,65-2,35)\end{array}$ & $\begin{array}{c}3,80 \\
(1,68-8,60)\end{array}$ & 1,00 & $\begin{array}{c}1,79 \\
(1,01-3,19)\end{array}$ & $\begin{array}{c}5,49 \\
(2,55-11,8)\end{array}$ & 1,00 & $\begin{array}{c}3,07 \\
(1,42-6,61)\end{array}$ \\
\hline & Positivo & 1,00 & $\begin{array}{c}1,24 \\
(0,83-1,84)\end{array}$ & $\begin{array}{c}2,09 \\
(1,37-3,20)\end{array}$ & $\begin{array}{c}2,75 \\
(1,44-5,25)\end{array}$ & 1,00 & $\begin{array}{c}1,70 \\
(1,19-2,43)\end{array}$ & $\begin{array}{c}2,23 \\
(0,97-4,07)\end{array}$ & 1,00 & $\begin{array}{c}1,31 \\
(0,71-2,44)\end{array}$ \\
\hline \multicolumn{11}{|c|}{ Relacionamentos } \\
\hline \multirow{2}{*}{$\begin{array}{l}\frac{0}{0} \\
\sum_{0}^{0} \\
0 \\
0\end{array}$} & Negativo & 1,00 & $\begin{array}{c}1,79 \\
(0,47-6,39)\end{array}$ & $\begin{array}{c}2,09 \\
(0,48-9,08)\end{array}$ & $\begin{array}{c}0,49 \\
(0,08-3,07)\end{array}$ & 1,00 & $\begin{array}{c}1,21 \\
(0,47-3,07)\end{array}$ & $\begin{array}{c}0,28 \\
(0,06-1,24)\end{array}$ & 1,00 & $\begin{array}{c}0,23 \\
(0,07-0,78)\end{array}$ \\
\hline & Positivo & 1,00 & $\begin{array}{c}0,95 \\
(0,52-1,75)\end{array}$ & $\begin{array}{c}0,97 \\
(0,49-1,92)\end{array}$ & $\begin{array}{c}1,77 \\
(0,72-4,36)\end{array}$ & 1,00 & $\begin{array}{c}1,02 \\
(0,64-1,62)\end{array}$ & $\begin{array}{c}1,86 \\
(0,89-3,90)\end{array}$ & 1,00 & $\begin{array}{c}1,83 \\
(1,01-3,33)\end{array}$ \\
\hline \multirow{2}{*}{ 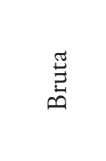 } & Negativo & 1,00 & $\begin{array}{c}0,57 \\
(0,37-0,88)\end{array}$ & $\begin{array}{c}0,53 \\
(0,34-0,82)\end{array}$ & $\begin{array}{c}0,60 \\
(0,35-1,02)\end{array}$ & 1,00 & $\begin{array}{c}0,93 \\
(0,67-1,29)\end{array}$ & $\begin{array}{c}1,05 \\
(0,66-1,66)\end{array}$ & 1,00 & $\begin{array}{c}1,13 \\
(0,71-1,79)\end{array}$ \\
\hline & Positivo & 1,00 & $\begin{array}{c}0,52 \\
(0,36-0,75)\end{array}$ & $\begin{array}{c}0,66 \\
(0,45-0,95)\end{array}$ & $\begin{array}{c}0,58 \\
(0,37-0,92)\end{array}$ & 1,00 & $\begin{array}{c}1,27 \\
(0,98-1,66)\end{array}$ & $\begin{array}{c}1,13 \\
(0,78-1,65)\end{array}$ & 1,00 & $\begin{array}{c}0,89 \\
(0,61-1,29)\end{array}$ \\
\hline \multicolumn{11}{|c|}{ Avaliação global do estilo de vida } \\
\hline \multirow{2}{*}{$\underset{己}{\tilde{E}}$} & Negativo & 1,00 & $\begin{array}{c}1,46 \\
(0,71-3,01)\end{array}$ & $\begin{array}{c}1,12 \\
(0,53-2,38)\end{array}$ & $\begin{array}{c}2,82 \\
(1,26-6,33)\end{array}$ & 1,00 & $\begin{array}{c}0,77 \\
(0,45-1,32)\end{array}$ & $\begin{array}{c}1,93 \\
(1,05-3,57)\end{array}$ & 1,00 & $\begin{array}{c}2,51 \\
(1,32-4,80)\end{array}$ \\
\hline & Positivo & 1,00 & $\begin{array}{c}0,85 \\
(0,61-1,18)\end{array}$ & $\begin{array}{c}1,09 \\
(0,78-1,51)\end{array}$ & $\begin{array}{c}1,02 \\
(0,67-1,56)\end{array}$ & 1,00 & $\begin{array}{c}1,28 \\
(0,99-1,65)\end{array}$ & $\begin{array}{c}1,20 \\
(0,83-1,75)\end{array}$ & 1,00 & $\begin{array}{c}0,94 \\
(0,65-1,37)\end{array}$ \\
\hline
\end{tabular}

Em relação à atividade física constatou-se na análise bruta que os docentes com até 29 anos (12,5\%) apresentaram comportamentos negativos menos frequentes que os professores com idade entre 30 e 39 anos $(23,1 \%)$ e 50 anos ou mais (22,9\%). Além disso, os docentes entre 30 e 39 anos $(23,1 \%)$ relataram com maior frequência comportamentos negativos que os docentes com idade entre 40 e 49 anos (16,9\%).

$\mathrm{Na}$ avaliaçáo do componente comportamento preventivo evidenciou-se na análise bruta que os docentes com idade superior a 50 anos $(13,9 \%)$ adotam com maior frequência comportamentos negativos que os professores com até 29 anos (9,5\%), 30 a 39 anos $(5,6 \%)$ e 40 a 49 anos (6,3\%). Destaca-se ainda que os professores com idade entre 40 e 49 anos $(6,3 \%)$ relataram comportamentos negativos mais frequentes que os docentes entre 30 e 39 anos (5,6\%). Por outro lado, os professores com até 29 anos de idade $(73,5 \%)$ apresentaram com menos frequência comportamentos positivos que os docentes entre 40 e 49 anos $(84,4 \%)$ e 50 anos ou mais $(79,6 \%)$. Além disso, os docentes que possuem entre 30 e 39 anos 
(79,5\%) possuíam comportamentos positivos menos frequentes que os de 40 a 49 anos $(84,4 \%)$.

O componente relacionamentos evidenciou razôes de chances tanto no primeiro quanto o segundo modelo de análise ajustada, sendo que os docentes entre 40 e 49 anos $(6,7 \%)$ apresentavam com maior frequência comportamentos negativos que os de 50 anos ou mais $(4,5 \%)$. Além disso, os professores com 50 anos ou mais $(81,1 \%)$ adotavam com maior freqüência comportamentos positivos que os de 40 a 49 anos de idade $(77,4 \%)$.

No componente controle do estresse, a análise bruta constatou que os professores com até 29

\section{Discussão}

Os maiores percentuais de professores concursados nos magistérios públicos estaduais da região sul do Brasil encontram-se nos ciclos vitais de 30 a 39 anos e 40 a 49 anos. Além disso, uma proporção semelhante de docentes está nas extremidades da amostra dos ciclos vitais, o que pode representar uma renovação simétrica do contingente laboral atual, quando considerada a região sul do Brasil. Entretanto, ao observar as especificidades de cada unidade federativa, constatam-se algumas diferenças observadas na TABELA 1. Tais evidências indicam que, no futuro próximo, haverá a necessidade de maior número de contrataçóes de professores de Educação Física nos estados de Santa Catarina e Rio Grande do Sul, caso o fluxo de alunos no ensino básico se mantenha.

Em relação aos pontos de corte estabelecidos neste estudo para os ciclos vitais, observou-se que a maioria dos docentes apresenta características sócio-demográficas e profissionais similares ao estudo descrito por SIKES ${ }^{21}$, no qual descreve que os docentes com até 29 anos apresentaram-se com características do início da vida adulta. Os professores com idade entre 30 e 39 anos estavam em uma faixa de transição, ou seja, possuem maior estabilidade que os docentes com até 29 anos, assim, consequentemente, buscam constituir uma família. Os docentes com 40 a 49 anos ou com 50 anos ou mais apresentaram estar em uma fase de estabilização, embora que os docentes com 50 anos ou mais demonstravam maiores índices em características associadas à aposentadoria docente (tempo de serviço e ciclo de desenvolvimento profissional).

Destaca-se ainda o fato do ciclo de 30 a 39 anos possuir maior índice de docentes pós-graduados, o anos $(24,0 \%)$ relataram comportamentos negativos mais frequentes que os docentes com 30 a 39 anos $(22,1 \%)$ e 40 a 49 anos $(18,3 \%)$. Por outro lado, os docentes com até 29 anos (57,0\%) adotavam com maior frequência comportamentos positivos que aqueles entre 30 e 39 anos (47,5\%), 40 e 49 anos $(54,2 \%)$ e 50 anos ou mais $(50,2 \%)$.

A análise bruta da avaliação global do estilo de vida evidenciou que os professores com até 29 anos (4,2\%), 30 a 39 anos $(6,7 \%)$ e 40 a 49 anos $(4,4 \%)$ adotavam com menor frequência comportamentos negativos do que os docentes com 50 anos de idade ou mais $(10,9 \%)$.

que pode estar atrelado à maior oferta de cursos de especializaçáo lato sensu nas décadas de 90 e 2000. Tais cursos auxiliam o professor na entrada da carreira do magistério público a partir de maior pontuação na prova de títulos nos concursos públicos, como também é um fator para aumentar os honorários dos professores ${ }^{32}$.

Sobre o constructo da satisfação no trabalho, os docentes de Educação Física relataram baixa satisfação com relação à remuneração, condições de trabalho, integração social no ambiente de trabalho e trabalho e espaço total de vida, o que não difere de outras investigaçóes brasileiras ${ }^{3-4}$ e internacionais ${ }^{5-9}$.

Os maiores níveis de satisfação foram encontrados nos indicadores oportunidade de progressáo na carreira, autonomia no trabalho, leis e normas do trabalho e relevância social do trabalho. Estas evidências podem estar atreladas à estabilidade no emprego adquirida a partir de ingresso por meio de concurso público, bem como garantida nos estatutos dos magistérios estaduais ${ }^{33-35}$.

Em relação às associaçôes entre o constructo da satisfação no trabalho com os ciclos vitais, constatou-se que as dimensóes remuneração e condiçôes de trabalho demonstraram associações, tanto na análise bruta quanto no primeiro e segundo modelos ajustados, o que demonstra a forte relação que estas dimensóes do trabalho possuem ao longo da vida do docente, independente da existência de variáveis moderadoras ou não, quando considerados os aspectos sócio-demográficos e profissionais e os parâmetros individual e socioambiental.

No caso especifico da remuneração, observou-se que docentes com até 29 anos apresentaram o maior índice de satisfação, o que pode estar associado ao ingresso no mercado de trabalho por meio de 
um emprego estável e com maior proteçâo social. Além disso, é neste período da vida que o docente apresenta maior entusiasmo para desenvolver um bom trabalho pelo fato de adentrar no mercado de trabalho $^{36}$, bem como, busca demonstrar uma boa atuação profissional, conforme os conhecimentos assimilados durante a formação inicial ${ }^{37}$.

Em relação às condiçôes de trabalho, constatou-se que os docentes com 30 a 39 anos apresentaram o maior índice de insatisfação, o que pode estar atrelado às características do ciclo de diversificação que estes docentes se encontram no desenvolvimento profissional. De fato, é neste estágio da carreira que ocorre maior busca pela pós-graduaçáo, a qual pode elevar a sensibilização da necessidade de melhoria das condiçõos da educação ${ }^{24}$. Por outro lado, o menor índice de satisfação apresentado pelos professores que possuem até 29 anos pode estar associado ao "choque de realidade", o qual ocorre frequentemente quando o estudante conclui o curso de graduaçáo e se insere no mercado de trabalho e observa que a qualidade dos equipamentos ofertados na realidade da escola pública está muito distante do ideal preconizado pelos cursos de formação inicial ${ }^{18,23-24}$.

$\mathrm{Na}$ análise dos aspectos legais da carreira docente considerando os ciclos vitais foi necessário considerar todas variáveis dos constructos da satisfação no trabalho e do estilo de vida, além dos aspectos sóciodemográficos e profissionais como moderadoras na análise da regressão logística multinomial. Isto se deve a amplitude e importância das questóes legais ao longo da vida do docente, pois dependendo dos sentimentos e comportamentos, bem como das características sócio-demográficas e profissionais dos professores, há possibilidade de alteração da percepção do docente em relação às leis que regem o seu trabalho. Assim, não é apenas o endereço social que determina o sentimento de aprovaçáo e/ou reprovação das leis e normas do trabalho, mas também as demais questóes que afetam o Bem Estar do Trabalhador Docente.

Um exemplo dessa constatação é o maior índice de insatisfação observado nos professores de 50 anos ou mais, que parece resultar das incertezas do processo de aposentadoria, atreladas à instabilidade das leis que a regem e à frágil estrutura das instituições que são responsáveis pelo pagamento dos benefícios aos docentes jubilados. Além disso, tal fato pode estar associado à moderada correlação apresentada entre os aspectos legais com a progressão na carreira de docentes ${ }^{12}$, pois se observa que os professores mais experientes demonstram menor percepção de satisfação na progressão na carreira ${ }^{8}$.
As associaçôes demonstradas entre os ciclos vitais e oportunidade de progressão da carreira e trabalho e espaço total de vida, quando consideradas apenas as principais variáveis moderadoras, ressalta a influência dos fatores mais importantes que alteram sentimentos e comportamentos dos docentes. Considerando esta perspectiva, na avaliação da progressão da carreira foi observado que os professores que possuem 50 anos ou mais apresentaram menor nível de satisfação, supostamente porque não podem mais progredir na carreira por estarem no último nível de progressão, ou mesmo, próximos da aposentadoria. A maior satisfação da progressão na carreira evidenciada entre os docentes mais novos deve-se ao fato da possibilidade mais frequente de ter acesso à progressáo nos planos de cargos e salários ${ }^{8}$, além da possibilidade de sair do estágio probatório, período no qual a ação laboral dos professores é constantemente avaliada.

$\mathrm{O}$ menor índice de insatisfação dos docentes com 50 anos ou mais em relação ao tempo dedicado ao lazer e ao trabalho, quando comparado com os professores com 40 a 49 anos, pode ser reflexo do afastamento gradativo do trabalho dos docentes que estão no último ciclo. Por outro lado, os professores com idade entre 40 e 49 anos apresentam algumas dificuldades em tarefas administrativas da escola, como o preenchimento de novos modelos de diários de classe e de relatórios ${ }^{21}$, visto que é comum a realização destas açóes fora do horário de trabalho na escola ${ }^{3}$.

No momento em que se avaliou o computo geral da satisfação no trabalho, constatou-se a existência de associação significativa, tanto na análise bruta quanto na análise que considera as variáveis moderadoras mais importantes, o que demonstra que as mudanças de percepçóes ocorrem quando são considerados poucos fatores que possam intervir na satisfação docente. Por outro lado, quando consideradas diversas variáveis moderadoras, sem estabelecer um critério rígido para a participação na análise, evidencia-se a não significância da satisfação do trabalho ao longo da vida do docente, o que pode ser vinculado à diversidade de assuntos que interferem na análise.

Quando encontradas associaçóes significativas na avaliação global da satisfação no trabalho, constatouse que os maiores níveis de satisfação e insatisfação foram relatados pelos docentes que possuem 50 anos ou mais. Tais evidências parecem estar associadas às duas características mais frequentes neste período da vida, as quais indicam o afastamento amargo ou sereno da profissão. Ou seja, o docente pode 
observar que as açóes realizadas no decorrer da sua carreira foram importantes para a sua vida pessoal e profissional, o que caracteriza o afastamento sereno da profissão. Mas, por outro lado, pode ocorrer a autorreflexão negativa da sua ação laboral, o que é demonstrada pelo afastamento amargo da ação docente ${ }^{21,23}$. Além disso, nos últimos anos de trabalho é comum o docente diminuir a cobrança para com os alunos ${ }^{21}$, o que pode reduzir o sentimento de desgaste com o trabalho no magistério.

Em relação ao estilo de vida encontrou-se evidências similares em investigaçóes realizadas com professores de Educação Física do Brasil ${ }^{10}$, da Suécia ${ }^{11}$ e do Qatar ${ }^{9}$, nas quais destacaram que problemas dos docentes eram: os maus hábitos alimentares, a falta do controle do estresse e a falta de atividades físicas. Destaca-se que embora tais problemas estejam relacionados a uma perspectiva individual, os fatores externos associados a outros aspectos vinculados as condiçóes de vida das pessoas podem interferir nas escolhas e atitudes tomadas pelos sujeitos, o que automaticamente interfere nos comportamentos frente ao estilo de vida ${ }^{38}$.

Ao considerar os ciclos vitais observou-se que apenas na análise bruta da regressão logística multinomial foi possível identificar relaçôes significativas nos componentes: alimentação, atividade física, comportamento preventivo, controle do estresse, além da avaliação global do estilo de vida. Tais evidências ressaltam a relação simples que os comportamentos do estilo de vida possuem no cotidiano da vida das pessoas em diferentes ciclos vitais.

$\mathrm{Na}$ avaliação global do estilo de vida, os docentes com 50 anos ou mais possuíam a maior frequência de comportamentos negativos. Dados similares foram encontrados por Acioly ${ }^{39}$ com professores de Educação Física do município de Florianópolis (Brasil). Além disso, observou-se no presente estudo que os componentes do estilo de vida apresentaram diferentes tendências de comportamentos quando considerados os ciclos vitais, o que é justificado pela abrangência do constructo do estilo de vida, o qual apresenta conteúdos mais heterogêneos ${ }^{12,30}$.

Sobre a alimentação, constatou-se que tanto os professores deste estudo, quanto em trabalhadores da indústria ${ }^{40}$, que possuem 40 anos ou mais tendem a demonstrar melhores hábitos alimentares. Destaca-se que esta evidência pode ser resultante do abandono do pluriemprego, pois trabalhar em dois ou mais locais pode afetar negativamente o comportamento alimentar ${ }^{41}$.

Em relaçáo à atividade física, similar ao observado em jovens trabalhadores da indústria ${ }^{40}$, constatou-se que os professores com até 29 anos são menos inativos fisicamente, o que parece estar relacionado ao deslocamento ativo no trajeto casa-escola-casa, ou mesmo, na troca de local de trabalho durante os turnos e nas açóes laborais realizadas em outras atividades, como academias e treinamento de equipes esportivas. Por outro lado, os docentes com 30 a 39 anos relataram a maior frequência de comportamentos negativos sobre a atividade física, o que pode estar relacionado à fase de transição dos ciclos vitais, a qual busca a estabilização na vida adulta ${ }^{21}$. Importante ressaltar que a falta da realização de atividades físicas voltadas à saúde está associada à ocorrência de lesóes crônicas em professores de Educaçáo Física pelo alto desgaste da sua função laboral ${ }^{15}$, o que pode ser um agravante para o afastamento, ou mesmo, abandono precoce da carreira docente.

Nos comportamentos preventivos, embora os resultados evidenciassem que todos os ciclos vitais apresentaram elevados índices de comportamento positivo (valores superiores a 70\%), observou-se que os professores com 40 anos ou mais de idade possuem os maiores índices negativos, o que pode estar atrelado à falta de políticas públicas de acompanhamento e manutenção da saúde dos trabalhadores da educação $\mathrm{o}^{42}$. Por outro lado, os docentes com até 39 anos evidenciaram as menores frequências de comportamento positivo. De fato, Palma et al. ${ }^{43}$ descreveram, em pesquisa realizada com estudantes universitários de Educação Física, que existe a falta de comportamentos preventivos em uma parcela dos estudantes, sendo que o comportamento náo adequado no momento do curso de graduaçáo pode se perpetuar na vida profissional.

Sobre o controle do estresse, os professores com até 29 anos apresentaram os maiores índices positivos e negativos. De fato, os docentes mais novos podem apresentar os comportamentos negativos por terem: expectativas menos realistas e poucas habilidades no enfrentamento de situaçóes estressantes, além do fato de que os docentes mais velhos são mais maduros e estáveis. Entretanto, a facilidade de adaptação às situaçóes estressantes, comportamento comum em início de carreira, pelo fato de existir diversas situaçóes desconhecidas a serem enfrentadas na unidade educativa, é um dos pontos positivos do grupo de professores mais jovens ${ }^{44}$.

Quando avaliado o componente relacionamentos, o qual se apresenta como um tema mais subjetivo do constructo do estilo de vida, constatou-se a necessidade da utilização de variáveis moderadoras para encontrar alguma relaçáo significativa com os ciclos vitais. Nestas análises, os professores com 40 
a 49 anos demonstraram maior frequência de comportamento negativo que os docentes com 50 anos ou mais. Estes resultados são similares ao modelo teórico dos ciclos vitais de SiKes ${ }^{21}$, o qual relata que os professores com 50 anos ou mais relaxam na disciplina e cobranças com os alunos, o que ameniza as discussôes com os alunos. Por outro lado, a preocupação pela manutenção das tradiçôes escolares é mais comum entre os docentes com 40 a 49 anos, sendo que o não aceitar estas tradições tem como consequência experimentar situaçôes desagradáveis na unidade educativa, as quais provocam problemas de relacionamento com a comunidade escolar.

Em relação às limitações do estudo, ressaltam-se dois aspectos. O primeiro está associado às diferentes politicas implantadas nos magistérios públicos estaduais, as quais podem alterar a percepção e os comportamentos dos docentes, e consequentemente, interferir na avaliação conjunta dos três estados da regiấo sul do Brasil. $\mathrm{O}$ segundo aspecto está vinculado ao baixo número de instrumentos que retornaram aos pesquisadores $(28,69 \%)$. Destaca-se que mesmo assim, foi possível estabelecer uma boa representatividade de professores em cada estado e dos NREs para estabelecer um erro amostral aceitável para o estudo, pelo fato do grande número de questionários enviados (5.734). Ressalta-se que embora a taxa de retorno fosse abaixo do esperado para estudos desta natureza, constata-se que na realidade brasileira o retorno foi considerável, pelo fato de não existir na realidade nacional a cultura do participante de pesquisas receber questionários via correio, responder e remeter o instrumento aos pesquisadores.

Ao considerar os resultados apresentados, concluise que os pontos de corte utilizados neste estudo foram eficientes para delimitar os ciclos vitais e assim favorecer a identificação de características marcantes dos aspectos sócio-demográficos e profissionais dos professores de Educação Física. Destaca-se que os docentes mais novos, com até 29 anos de idade, estáo na fase de descoberta da vida adulta; os professores entre 30 e 39 anos apresentaram características de pertencerem à fase de transição entre a descoberta da vida adulta e a estabilização; já os professores de 40 a 49 anos e 50 anos ou mais de idade demonstraram características de uma vida estável; e os professores com 50 anos ou mais demonstram características mais próximas da aposentadoria.

Em relação às associaçôes entre os ciclos vitais e os constructos da satisfação no trabalho e do estilo de vida, constatou-se que os indicadores como condiçóes de trabalho e remuneração apresentam forte associação com diversas fases da vida dos docentes. Entretanto, assuntos como oportunidade de progressão na carreira e trabalho e espaço total de vida demonstram associação apenas quando considerados os fatores moderadores mais importantes, diferente dos aspectos legais, o qual demonstrou associação apenas quando consideradas diversas variáveis moderadoras. Tais resultados afetaram os resultados da avaliação global da satisfação no trabalho, a qual evidenciou associaçáo quando considerados as variáveis moderadoras mais importantes na análise, ou mesmo, quando avaliada em uma análise mais simples entre os ciclos vitais e a avaliação global da satisfação no trabalho. Ao considerar o constructo da satisfação no trabalho, constatou-se que a utilização de variáveis moderadoras nas análises auxiliou na compreensão das alteraçóes de percepçóes dos professores ao longo da vida, as quais ficariam despercebidas caso avaliassem apenas no método da análise bruta da regressão logística multinomial.

A avaliação do constructo do estilo de vida demonstrou situaçáo contrária, a qual revelou que a análise simples, na forma bruta da regressão logística multinomial, foi a principal maneira de observar diferenças significativas nos componentes: alimentação, atividade física, comportamento preventivo e controle do estresse, bem como na avaliaçáa global. Apenas o componente relacionamentos necessitou variáveis moderadoras para demonstrar diferenças significativas, o que pode estar associado à questão subjetiva da qualidade das relaçóes pessoais individuais e em grupo que os docentes possuem ao longo dos ciclos vitais.

Os ciclos vitais evidenciaram diferentes tendências de comportamentos do estilo de vida e das percepçóes sobre o trabalho, o que ressalta a importância da avaliação conjunta dos parâmetros socioambiental e individual do Bem Estar do Trabalhador Docente em Educação Física para uma melhor compreensão dos diferentes momentos da vida dos professores.

Com base nas evidências apresentadas neste estudo, sugerem-se algumas ações que devem ser realizadas para favorecer a manutenção e a melhoria do Bem Estar do Trabalhador Docente em Educação Física, sendo elas: melhoria da qualidade das condiçóes de ensino; salários adequados que favoreçam o afastamento do pluriemprego, o qual interfere na relação entre o tempo de trabalho e o tempo de lazer; politicas que busquem a minimização da indisciplina escolar o que irá favorecer o controle do estresse docente; regimentos claros nos processos eleitorais das direçôes escolares, no sentido de assegurar a elaboração de planos de ação a serem 
assumidos pelos candidatos envolvidos no pleito para a direção, minimizando as divergências sobre os rumos que os diretores possam acenar às respectivas unidades educativas; revisão do teto máximo para a progressão na carreira docente; e, implantação de programas que incentivem uma alimentação saudável para todos os docentes, bem como, açóes que promovam atividades físicas, principalmente direcionadas aos docentes mais experientes.
Por fim, a necessidade de realizar novos estudos é recomendada para abordar, tanto a partir de perspectiva qualitativa quanto de perspectiva quantitativa, os constructos da satisfação do trabalho e do estilo de vida com os ciclos vitais, no sentido de auxiliar na compreensão da vida do docente e na definição de programas e políticas públicas nos magistérios públicos estaduais que favoreçam o estado de saúde e o Bem Estar do Trabalhador Docente.

\begin{abstract}
Wellness of physical education teacher of southern region of Brazil according to the life cycles

The aim of the study was to evaluate association between the life cycles and the social-environmental (work satisfaction) and individual (lifestyle) parameters of Wellness in Physical Education Teacher from the public teaching southern region of Brazil. In the investigation, 1645 teachers answered a socialdemographic and professional questionnaire, as well as the OVT-PEF and PEVI tools. The chi-square, likelihood ratio and multinomial logistic regression, in the original form and in two adjusted models, were used for evaluating the associations. The results demonstrated that the use of moderating variables in the adjusted analyses of work satisfaction construct helped in understanding the teachers's perceptions changes across the life. Contrary situation was demonstrated in lifestyle evaluation, which revealed that the original model analysis was the principal manner of observing significant differences in most of the components and in the general computation.
\end{abstract}

KEY WORDS: Age range; Teacher career; Work satisfaction; Lifestyle; Teachers; Physical education.

\title{
Referências
}

1. Both J, Nascimento JV. Intervenção profissional na educação física escolar: considerações sobre o trabalho docente. Movimento. 2009;15:169-86.

2. Araújo JD. O custo da doença: revisão de literatura. Rev Saúde Pública. 1975;9:229-38.

3. Molina Neto V. A prática dos professores de educação física nas escolas públicas de Porto Alegre. Movimento. 1998;9:31-46.

4. Tokuyochi Jh, Bigotti S, Antunes FHC, et al. Retrato dos professores de educaçáo física das escolas estaduais do Estado de São Paulo. Motriz. 2008;14:418-28.

5. MacDonald D. The role of proletarianization in physical education teacher attrition. Res Q Exerc Sport. 1995;66:129-41.

6. Smyth DM. First-year physical education teachers' perceptions of their workplace. J Teach Phys Educ. 1995;14:198-214.

7. Smith D, Leng GW. Prevalence and sources of burnout in Singapore secondary school physical education teachers. J Teach Phys Educ. 2003;22:203-18.

8. Koustelios A. Physical education teachers in Greece: are they satisfied? Int J Phys Educ. 2005;42:85-90.

9. Al-Mohannadi A, Capel S. Stress in physical education teachers in Qatar. Social Psychol Educ. 2007;10:55-75.

10. Bara Filho MG, Biesek S, Fernandes APT, Araújo CGS. Comparação do padrão de atividade física e peso corporal pregressos e atuais entre graduados e mestres em educação física. Rev Bras Ciênc Esporte. 2000;21:30-5.

11. Sandmark H. Musculoskeletal dysfunction in physical education teachers. Occup Environ Med. 2000;57:673-77.

12. Both J, Nascimento JV, Sonoo CN, Lemos CAF, Borgatto AF. Condições de vida do trabalhador docente: associação entre estilo de vida e qualidade de vida no trabalho de professores de educação física. Motricidade. 2010;6:39-51.

14. Andrews JC. O stress nos professores de educaçáo física dos nossos dias: uma perspectiva internacional. Bol Soc Port Educ Fís. 1993;7/8:13-25. 
13. Both J, Nascimento JV, Borgatto AF. Estilo de vida dos professores de educação física ao longo da carreira docente no Estado de Santa Catarina. Rev Bras Ativ Fís Saúde. 2007;12:54-64.

15. Lemoyne J, Laurencelle L, Lirette M, Trudeau F. Occupational health problems and injuries among Quebec's physical educators. Appl Ergon. 2007;38:625-34.

16. Burden PR, Teacher development. In: Houston WR, Haberman M, Sikula J, organizers. Handbook of research on teacher education. New York: MacMillian; 1990.

17. Cavaco MH. Oficio do professor: o tempo e as mudanças. In: Novoa A, organizador. Profissão professor. Porto: Porto Editora; 1995.

18. Garcia CM. Formación del profesorado para el cambio educativo. Barcelona: EUB; 1995.

19. Sprinthall NA, Reiman AJ, Thies-Sprinthall L. Teacher professional development. In: Sikula J, Buttery TJ, Guyton E. Handbook of research on teacher education. New York: MacMillan; 1996.

20. Tardif M, Raymond D. Saberes, tempo e aprendizagem do trabalho no magistério. Educ Soc. 2000;21:209-44.

21. Sikes P. The life cycle of the teacher. Ball SJ, Goodson IF, organizers. Teachers' lives and careers. London: Falmer; 1985.

22. Gonçalves JA. A carreira dos professores de ensino primário. In: Novoa A, organizador. Vidas de professores. Porto: Porto Editora, 1995.

23. Huberman M. O ciclo de vida profissional de professores. In: Novoa A, organizador. Vidas de professores. Porto: Porto Editora, 1995.

24. Nascimento JV, Graça A. A evolução da percepção de competência profissional de professores de educação física ao longo de sua carreira docente. 6. Congresso de Educação Física e Ciências dos Desportos dos Países de Língua Portuguesa; 1998; La Coruña, ES. La Coruña: INEF; 1998. [CD ROM].

25. Ramzaninezha R, Hemmatinezhad MA, Nejadsajadi A, Keshtan MH. Job retention factors among physical educators. World J Sport Sci. 2009;2:154-9.

26. Canabarro LK, Neutzling MB, Rombaldi AJ. Nível de atividade física no lazer dos professores de educação física no ensino básico. Rev Bras Ativ Fís Saúde. 2011;16:11-7.

27. Both J, Nascimento JV, Lemos CAF, et al. Qualidade de vida no trabalho de professores de educação física. Rev Bras Cineantropom Desempenho Hum. 2006;8:45-52.

28. Nahas MV, Barros MGV, Francalacci V. O pentáculo do bem estar: base conceitual para a avaliação do estilo de vida em indivíduos ou grupos. Rev Bras Ativ Fís Saúde. 2000;5:48-59.

29. Walton RE. Quality of working life: what is it? Sloan Manage Rev. 1973;15:11-21.

30. Both J, Borgatto AF, Nascimento JV, Sonoo CN, Lemos CAF, Nahas MV. Validaçáo da escala "perfil do estilo de vida individual". Rev Bras Ativ Fís Saúde. 2008;13:5-14.

31. Lemos CAF. Qualidade de vida na carreira profissional de professores de Educação Física do magistério público estadual/ RS [dissertação]. Florianópolis: Universidade Federal de Santa Catarina, Centro de Desportos; 2007.

32. Valle IR. Carreira do magistério: uma escolha profissional deliberada? Rev Bras Estud Pedagóg. 2006;216:178-87.

33. Rio Grande do Sul (Estado). Lei n. 6.672. Estatuto e plano de carreira do magistério público do Rio Grande do Sul. Diário Oficial, Porto Alegre (1974 abr 22).

34. Santa Catarina (Estado). Lei n. 6.844. Dispóe sobre o estatuto do magistério público estadual do Estado de Santa Catarina. Diário Oficial, Florianópolis (1986 jul 29).

35. Paraná (Estado). Lei complementar n. 103. Institui e dispóe sobre o plano de carreira do professor da rede estadual de educação básica do Paraná e adota outras providências. Diário Oficial, Curitiba (2004 mar 15).

36. Jabnoum N, Fook CY. Job satisfaction of secondary school teachers in Selangor, Malaysia. Int J Commerce Manag. 2001;11:72-90.

37. Nascimento JV. Formação profissional em educação física: contextos de desenvolvimento curricular. Montes Claros: Unimontes; 2002.

38. Vilarta R, Gonçalves A. Condiçóes de vida, modo de vida e estilo de vida. In: Gonçalves A, Vilarta R. Qualidade de vida e atividade física: explorando teoria e prática. Barueri: Manole; 2004.

39. Acioly PL. Estilo de vida e insatisfação referida quanto ao trabalho entre professores de educação física de Florianópolis [dissertação]. Florianópolis, (SC): Universidade Federal de Santa Catarina, Centro de Ciências da Saúde; 2005.

40. Barros MVG, Nahas MV. Comportamentos de risco, auto-avaliação do nível de saúde e percepção de estresse entre trabalhadores da indústria. Rev Saúde Pública. 2001;35:554-63.

41. Bohle P, Quinlan M, Kennedy D, Williamson A. Working hours, work-life conflict and heath in precarious and "permanent” employment. Rev Saúde Pública. 2004;38(Supl):19-25. 
42. Martins CO, Michels G. Programas de promoção da saúde do trabalhador: exemplos de sucesso. Rev Bras Cineantropom Desempenho Hum. 2003;5:85-90.

43. Palma A, Abreu RA, Cunha CA. Comportamentos de risco e vulnerabilidade entre estudantes de educação física. Rev Bras Epidemiol. 2007;10:117-26.

44. Danylchuk KE. The presence of occupational burnout and its correlates in university physical education personnel. J Sport Manag. 1993;7:107-21.

ENDEREÇO
Jorge Both

Centro de Educação Física e Esporte

Universidade Estadual de Londrina

Rod. Celso Garcia Cid, km 380 - Caixa Postal 6001

86051-980 - Londrina - Paraná - BRASIL

e-mail: jorgeboth@yahoo.com.br
Recebido para publicação: 05/09/2012

1a. Revisão: 10/05/2013

2a. Revisão: 20/08/2013

Aceito: 24/09/2013 